\section{References}

BRockington, I. (ed.) (1996) Motherhood and Mental Health. Oxford: Oxford University Press.

OATES, M. (1988) The development of an integrated community orientated service for severe postnatal illness. In Motherhood and Mental Illness: Causes and Consequences (eds. R. Kumar \& L. F. Brockington) London: Wright.

Royal College OF Psychiatrists (1992) Report of the General Psychiatry Section Working Party on Postnatal Illness. Psychiatric Bulletin, 16, 519-522.
*Meena Patel, Associate Specialist, Jona Lewin, Consultant Psychiatrist and Anne Stevens, Senior Clinical Nurse Specialist, Coombe Wood Mother and Baby Unit, Park Royal Centre for Mental Health, Central Middlesex Hospital, Acton Lane, London NW10 7NS

*Correspondence

\title{
Perceived role of psychiatrists in the management of substance misuse
}

\section{A questionnaire survey}

\author{
Edward Day, Jon Arcelus and Ashraf Kahn
}

\begin{abstract}
Nims and mothods A postal questionnaire sent to all psychiatrists working in four NHS trusts in and around Birmingham was used to survey the number of new cases of drug and alcohol misuse identified in the previous month and the degree of postgraduate training in the management of such cases. Attitudes and bellefs about substance misuse problems were also elicited.

Reeutts A response rate of $70 \%$ was achieved across six sub-speciallities in psychiatry and four levels of training. Of the 143 respondents, over half had identified at least one new case of alcohol (61\%) or drug misuse (55\%) in the previous month. Approximately half of the sample admitted to having recelved no training in management of substance misuse cases in the previous five years (45\% alcohol, $50 \%$ drugs). There was general agreement about the potential management role of the doctor in the field, but less consensus on whether the clinician had a responsibility to intervene in such cases. A clear discrepancy was demonstrated between psychiatrists' perceptions of the evidence supporting various treatments and the actual evidence base.

Cinical implications The study highlights the pressing need for training psychiatrists at all levels and in all subspeciallities in the management of substance misuse.
\end{abstract}

The management of substance misuse is currently very topical, and the 'Drug Czar's' report has raised the profile of addiction on the political agenda (President of the Council, 1998). Although doctors, and psychiatrists in particular, have a role in the detection of addicttive behaviours and their management, this may present a number of problems. As Unnithan et al (1994) suggest, there may be three particular areas of anxiety among general psychiatrists that lead to reluctance to provide care for those who misuse substances:

(a) 'role adequacy' - having the necessary information and skills in order to identify and respond appropriately;

(b) 'role legitimacy' - the extent to which management of such problems is felt to fall within their responsibility;

(c) 'role support' - the confidence in the existence and adequacy of help and advice when it might be needed.

The anxiety in the area of 'role adequacy' is underpinned by evidence to suggest that both undergraduate and postgraduate training oppor- 
tunities in the field are limited and that there is a pressing need to address the problem (Glass, 1989; Glass-Crome, 1992; Crome, 1999). In the last decade the evidence base regarding effective treatment has been accumulating steadily (Project MATCH Research Group, 1997), but it is not clear that psychiatrists have sufficient skills to assess and manage the less complicated cases, while referring the more dependent and chaotic to addiction specialists. Thus, it can be argued that 'role support' is not utilised effectively. Most practising doctors will have also questioned 'role legitimacy'. Patients who misuse substances often elicit powerful negative emotions in doctors treating them, and the persistent nature of their problem or the severity of behavioural disturbance involved often fuel such feelings (Farrell \& Lewis, 1990).

A review of the UK literature revealed that many of these problems have not been extensively researched. While some research has focused on the primary health care team (Groves et al, 1996), little work has been directed towards non-specialist addiction psychiatrists. This study aims to provide some estimate of the experience and training of a sample of general psychiatrists and to survey their attitudes towards people who misuse substances.

\section{The study}

The personnel departments in four local NHS trusts (South Birmingham, North Birmingham, Sandwell and Solihull) were contacted, and each supplied a list of all psychiatrists working for them. This encompassed those working in general adult, older adult, forensic and child and adolescent psychiatry, as well as the regional psychotherapy unit. A total of 204 career psychiatrists were identified, including 74 consultants, 20 senior/specialist registrars, 47 'staff grade' doctors and 54 senior house officers. Each was sent a questionnaire with a prepaid return envelope, and a second copy was sent six weeks later.

The questionnaire was divided into two sections. The first concerned demographic data, including age, level of training (consultant, senior/specialist registrar, senior house officer or other) and current speciality. Subsequent questions enquired about the number of new cases of alcohol and drug misuse identified in the last month, giving five reply options ('none', 'one to two', 'three to five', 'six to ten', or 'greater than 10'). The issue of whether the respondent had received any training in either management of alcohol or drug-related problems in the past five years was then examined.

The second section consisted of 20 questions initially devised by Roche et al $(1995 a, b)$. These surveyed beliefs and opinions in three areas relevant to clinical practice:

(a) the medical practitioner's role in the management of drug and alcohol problems;

(b) factors influencing the prognosis for patients with alcohol and drug-dependency;

(c) beliefs about the strength of evidence of the efficacy of different types of intervention in alcohol misuse.

In (a) and (b) the doctor was asked to tick one of five boxes labelled 'strongly agree', 'agree', 'uncertain', 'disagree' and 'strongly disagree' to indicate level of agreement with each statement. In (c) a five-point scale with anchors labelled ' 1 (no evidence)' and ' 5 (good evidence)' was used.

\section{Findings}

Of the 204 doctors surveyed, 143 replied, giving a response rate of $70 \%$. Replies to the first section revealed that most respondents fell into the 30-39-year-old age range (48\%). Slightly more than a third were from consultants (38\%), nearly a half from training grades (senior/ specialist registrars $(19 \%)$ or senior house officers (29\%)) and a sixth (15\%) from senior clinical medical officers or clinical assistants. Approximately half of these doctors worked in general adult psychiatry (48\%), with the rest distributed among six other sub-specialities (child and adolescent, 12\%; older adult, 14\%; psychotherapy, 7\%; forensic, 9\%; learning disability, 8\%; rehabilitation, 3\%). Almost half (45\%) had identified at least one case of drug misuse in the previous month, and $12 \%$ had seen three or more. The equivalent figures for cases of alcohol misuse were $61 \%$ and $29 \%$. A significant number of the respondents had received no training at all in alcohol $(45 \%)$ or drug $(50 \%)$ problems in the last five years. A further $27 \%$ of the replies indicated less than eight hours of alcohol training, with an equivalent figure of $28 \%$ for drugs.

The responses to the second section are summarised in Table 1. Differences between consultants and trainee groups were analysed using a $\chi^{2}$-square test. Almost all respondents agreed that "a drug and alcohol history should be one of a doctor's regular diagnostic tools", and there was very little agreement with the statement that "a doctor can only intervene effectively to help the physical complications of substance misuse". Indeed, approximately $95 \%$ believed that a doctor can intervene effectively before physical dependence develops, and 90\% that such an early intervention can be successful. More consultants $(41 \%)$ than trainees $(35 \%)$ considered patients with alcohol and drug 
Table 1. Aftitudes and bellefs about substance misuse problems

\begin{tabular}{|c|c|c|}
\hline & $\begin{array}{l}\text { Consultants } \\
\text { Agree/Strongly } \\
\text { Agree (\%) } \\
n=54\end{array}$ & $\begin{array}{l}\text { Trainees } \\
\text { Agree/Strongly } \\
\text { Agree (\%) } \\
n=68\end{array}$ \\
\hline $\begin{array}{l}\text { 1. Patients with alcohol and drug problems are readily identifiable } \\
\text { 2. Intervention when a person is developing alcohol or other drug } \\
\text { problems is rarely successful }\end{array}$ & $\begin{array}{r}22(41 \\
4(7) .\end{array}$ & $\begin{array}{r}24(35) \\
8(12)\end{array}$ \\
\hline $\begin{array}{l}\text { 3. The medical practitioner has a responsibility to intervene in the } \\
\text { case of patients with alcohol and drug problems }\end{array}$ & $31(57)$ & $47(69)$ \\
\hline $\begin{array}{l}\text { 4. A drug and alcohol history should be one of a doctor's regular } \\
\text { diagnostic tools }\end{array}$ & $53(98)$ & $67(98)$ \\
\hline $\begin{array}{l}\text { 5. A medical practitioner can effectively intervene in the case of } \\
\text { alcohol and drug problems only when the physical dependence } \\
\text { has occurred }\end{array}$ & $3(5)$ & $5(7)$ \\
\hline $\begin{array}{l}\text { 6. A doctor's knowledge and skills allow effective intervention only } \\
\text { as regards the physical complications of alcohol and drug use }\end{array}$ & $1(2)$ & $0(0)$ \\
\hline $\begin{array}{l}\text { 7. Referral to community support groups and treatment centres } \\
\text { is an essential part of the management of drug and alcohol } \\
\text { problems }\end{array}$ & $36(67)$ & $53(78)$ \\
\hline \multicolumn{3}{|l|}{$\begin{array}{l}\text { 8. The following factors are influential determining the prognosis } \\
\text { for patients with alcohol and drug dependency problems }\end{array}$} \\
\hline $\begin{array}{l}\text { (a) Supportive relationships } \\
\text { (b) Motivation to recover }\end{array}$ & $\begin{array}{l}52(96) \\
52(96)\end{array}$ & $\begin{array}{l}68(100) \\
65(96)\end{array}$ \\
\hline (c) Appropriate management by doctor & $47(87)$ & $61(90)$ \\
\hline $\begin{array}{l}\text { (d) Early intervention by doctor or similar other } \\
\text { (e) Employment status }\end{array}$ & $\begin{array}{l}39(72) \\
32(59)\end{array}$ & $\begin{array}{l}57(84) \\
53(78)\end{array}$ \\
\hline (f) Body mass index & $7(13)$ & $3(4)$ \\
\hline \multicolumn{3}{|l|}{$\begin{array}{l}\text { 9. Below is a list of treatments for people with alcohol dependency and/ } \\
\text { or problem drinking. How good is the evidence, from controlled trials, } \\
\text { supporting the effectlveness of each of these interventions? }\end{array}$} \\
\hline (a) Alcoholics Anonymous & $32(59)$ & 30 (44) \\
\hline (b) Cognitive-behavioural therapy & $25(46)$ & $25(37)$ \\
\hline (c) In-patient rehabilitation programme & $23(43)$ & $24(35)$ \\
\hline (d) Brief advice by medical practitioner at early stage of problem & $21(39)$ & $24(35)$ \\
\hline (e) Training in controlled drinking & $15(28)$ & $6(9)$ \\
\hline (f) Alcohol sensitising drugs (e.g. antabuse) & $14(26)$ & $18(26)$ \\
\hline (g) Dynamic psychotherapy & $2(4)$ & $0(0)$ \\
\hline
\end{tabular}

'Trainees' refers to senior registrars, specialist registrars and senior house officers

problems readily identifiable $(P=0.538)$, but more trainees than consultants accepted that the medical practitioner had a responsibility to intervene $(69 \%$ and $57 \%$ respectively, $P=0.181)$. More trainees also considered referral to community support groups and treatment centres to be important $(P=0.164)$.

Responses concerning perceived factors influential in determining prognosis (Question 8) showed that there was a general belief in the importance of supportive relationships and motivation to recover, and to a lesser degree appropriate management by the doctor. However, more trainees than consultants considered early intervention by a trained person and employment status to be important $178 \%$ and $59 \%$ respectively, $P=0.026$ ). When respondents were asked to rate their assessment of the research evidence for the effectiveness of different management strategies for alcohol misuse (Question 9), only dynamic psychotherapy was generally considered of no proven effectiveness. The evidence for other suggested interventions was considered strong by between $25 \%$ and $50 \%$. Overall, Alcoholics Anonymous was rated effective by most respondents, but considerably more consultants believed it to have proven efficacy $(P=0.0907)$. Very few trainees believed that training in controlled drinking had any research evidence supporting it.

\section{Comment}

This was a small sample using a simple questionnaire, but the high response rate of $70 \%$ would suggest that the findings are reasonably representative. The survey across a range of subspecialities within psychiatry shows that over $60 \%$ of respondents had identified at least one new case involving alcohol misuse in the previous month. As the majority of the $30 \%$ of nonresponders were general adult psychiatrists, it is 
likely that this figure would have been higher had they replied. It was anticipated that psychiatrists would probably assess problems of alcohol misuse, but that new cases of drug misuse would be referred directly to local community drug services, thus by-passing psychiatry. Therefore, it is interesting that $45 \%$ of the sample had also identified a new case of drug misuse. This confirms that the problem is a significant one in the practice of many psychiatrists. Despite this, nearly half of these respondents had not received any training in the management of substance misuse in the previous five years. When combined with the estimate from one UK study that showed medical students were taught about alcohol misuse and dependency for approximately one minute per week during their five year training (Glass, 1989), it is not surprising that Unnithan et al (1994) question 'role adequacy'.

A large number of respondents (particularly consultants) considered that there was good research evidence for the efficacy of Alcoholics Anonymous, and less for brief early interventions. The actual published findings demonstrate quite the opposite, highlighting a gap between science and practice (Miller et al, 1995). Lack of awareness of recent advances in the field could be one explanation for the observation that a third of consultants who replied felt that referral to specialist services was not important.

The questions examining attitudes to substance misusers revealed a number of interesting contradictions. Psychiatrists clearly considered the drug and alcohol history to be an important tool. This contrasts with other research showing that admitting psychiatrists fail to record the alcohol consumption in a significant proportion of case notes (Farid et al, 1998). The study identified a clear role for doctors in the management of substance misuse problems, but a sizeable minority were uncertain of their responsibility to intervene. The importance of supportive relationships, motivation to recover, early intervention and appropriate management by a doctor in determining prognosis were widely agreed. However, trainee psychiatrists considered employment to be a more important factor than their seniors.

The findings support the commentators who suggest that serious thought must be given to increasing training in substance misuse for both undergraduates and postgraduates (Glass, 1989; Glass-Crome, 1992; Crome, 1999). Innovative schemes in training medical students and psychiatry trainees have been developed elsewhere, most notably in Australia and the USA (Walsh, 1995). The recent focus for services for people who misuse substances with serious mental illness must be underpinned by a proper grounding in management of both drug and alcohol problems for all psychiatrists.

\section{Acknowledgements}

We thank Dr A. Copello and Professor I. Crome for their helpful suggestions in writing this paper and Mrs A. Farmer for her assistance with the design of the questionnaire.

\section{References}

Crome, I. B. (1999) The trouble with training: substance misuse education in British medical schools revisited. Whate are the issues? Drugs: Education Prevention and Policy, 6, $111-123$.

FARID, B., BIRD, R. H. \& NAIK, B. (1998) Alcohol and smoking history on admission to a psychiatric hospital. Psychiatric Bulletin, 22, 432-435.

FARREL, M. \& LEWIS, G. (1990) Discrimination on the grounds of diagnosis. British Journal of Addiction, 86. 883-890.

GLASS, I. B. (1989) Undergraduate training in substance abuse in the United Kingdom. British Journal of Addiction, 84, 197-202.

Glass-CROME, I. B. (1992) Training: a vital ingredient for alcohol treatment services. Current Opinion in Psychiatry, 5, 436-440.

Groves, P., Heuston, J., Durand, M. A., et al (1996) The identification and management of substance misuse problems by general practitioners. Journal of Mental Health, 5, 183-193.

MILLER, W. R., BROWN, J. M., Simpson, T. L., et al (1995) What works? A methodological analysis of the alcohol treatment outcome literature. In Handbook of Alcoholism Treatment Approaches (eds R. K. Hester \& W. R. Miller), pp. 12-44. Boston: Allyn \& Bacon.

PRESIDENT OF THE CounclL (1998) Tackling Drugs to Build a Better Britain. The Government's 10-Year Strategy for Tackling Drug Misuse. London: The Stationery Office.

PROJECT MATCH RESEARCH GROUP (1997) Matching alcoholism treatments to client heterogeneity: project MATCH post-treatment drinking outcomes. Journal of Studies on Alcohol, 68, 7-29.

Roche, A. M., PARLe, M. D.. CAMPBell, J., et al (1995a) Substance abuse disorders: psychiatric trainees knowledge, diagnostic skills and attitudes. Australian and New Zealand Joumal of Psychiatry, 29. 645-652.

- - , StuBbs, J. M., et al (1995b) Management and treatment efficacy of drug and alcohol problems: what do doctors believe? Addiction, 80, 1357-1366.

UNNITHAN, S., RrTsON. B. \& STRANG. J. (1994) Organising treatment services for drug and alcohol misusers. In Seminars in Alcohol and Drug Misuse (eds J. Chick \& R. Cantwell). pp. 223-238. London: Gaskell.

WALSH, R. A. (1995) Medical education about alcohol: a review of its role and effectiveness. Alcohol \& Alcoholism. so. 689-702.

*Edward Day, Senior House Officer, Adult Service, Psychotherapy, Devon House, Mindelson Way, Off Vincent Drive, Edgbaston, Birmingham B18 5SD; Jon Arcelus, Specialist Registrar in Child \& Adolescent Psychiatry, Oaklands Centre, Selly Oak, Birmingham; and Ashraf Kahn, Consultant, Addictive Behaviours Centre, All Saints Hospital, Birmingham

*Correspondence 